\title{
There's never going to be a perfect school that ticks every box: minority perspectives of inclusion and placement preferences
}

\author{
Article \\ in \\ Journal of Research in Special Educational Needs \\ March 2018
}

This is an Accepted Manuscript of an article published in Journal of Research in Special Educational Needs in March 2018, available online: https://doi.org/10.1111/1471-3802.12418

To cite this article: Rizvi, S. (2018), There's never going to be a perfect school that ticks every box: minority perspectives of inclusion and placement preferences. J Res Spec Educ Needs. . doi:10.1111/1471-3802.12418 


\title{
There's never going to be a perfect school that
} ticks every box: minority perspectives of inclusion and placement preferences

\section{Dr. Sana Rizvi}

\author{
Division of Education Studies, School of Applied Social Sciences, De Montfort \\ University, Leicester, UK
}

Key words: Inclusion, placement preferences, SEND, minority families, qualitative research.

This study explores how British-Pakistani mothers of children with special education needs and/or disability (SEND) experience the school placement decision-making process, and the relationship between their notions of inclusion and different placement settings. This paper reports on the author's research and explores how professional expertise interacts with maternal concerns and knowledge. Using Weber's (2001) Intersectional Framework, this qualitative study was conducted in Southwest England in three phases using semi-structured interviews, unstructured interviews and vignettes. Eight first-generation and second-generation immigrant British-Pakistani mothers participated in this research, whose children varied in age and range of SEND. Research participants were contacted through Anoka, a South Asian disabled families' support group and through snowballing. Braun and Clarke's (2006) thematic analysis was used to develop five main themes. This research yielded rich and nuanced data regarding maternal understanding around placement preferences. Mothers generally preferred those special schools with plans for eventual mainstream integration, particularly those sharing geographical locations with a mainstream school. A uniquely telling finding in this study was that mothers preferred special schools which had the least disabling visual outlook and appeared least like a medicalised setting. In the case of mainstream schools, in addition to 
overall performance and educational attainment, mothers valued school policies towards accommodating pupils with SEND. Most notably, all mothers suggested that their child's SEND was their main criteria for placement preferences in order to secure better provisions. This research suggests that for parents from minority communities, the placement decisionmaking process must become more inclusive and enabling before they are able to fully support their child with SEND.

\section{Introduction}

Recent key government education policies and legislation have increasingly focused on including parental perspectives of special education, specifically their involvement in decisionmaking for their child with special education needs and/or disability (SEND). The new SEND Code of Practice (Department of Education and Department of Health, 2015) promotes 'the participation of children, their parents and young people in decision-making. . .[and] greater choice and control for young people and parents over support' (p. 19). A key aspect of parental decision-making which can be stressful is deciding their preferences for the type of school (mainstream or special) they want their child to attend. Every child has the right to be educated within mainstream school, and parents of children with SEND have the right to express a preference for their child's placement type. However, often this is not a fully exercised choice because the final placement decision rests with local authorities (LAs), who have to consider whether educating an individual child with SEND would adversely affect the education of typical children. Moreover, although parents can challenge the LA's decision, this does not guarantee that LAs will revise their initial placement decisions. 
Parents can have very different experiences and preferences regarding placement decisionmaking depending on their child's SEND, the school and familial factors (Byrne, 2013). Two recent studies by Mann, Cuskelly and Moni (2015) and Bajwa-Patel and Devecchi (2014) have highlighted the various mechanisms within parental placement decision-making. In their Australian qualitative research using focus groups with 30 parents of typical children and children with SEND, Mann, Cuskelly, and Moni (2015) outlined three mechanisms affecting parental choice in decision-making for children with SEND. The first consideration is individual freedom versus constraints on choice; while 'choice' inherently implies freedom to choose from different options, in reality parental choice is exercised in the context of societal and institutional limitations. The second consideration is the perceived value on individual agency versus professional expertise; parents may either be gently guided in a particular direction or coerced into making certain choices by professionals. The final consideration is whether parental decision-making is a rational or an emotional decision; do parents utilise a cost-versus-benefit approach to each placement setting? Applying the first mechanism, Mann, Cuskelly, and Moni (2015) revealed that parents of children with SEND generally experienced more constraints to choose than parents of typical children. They found that families of children with SEND were pressured by teachers to pursue special schools if their child was eligible for special school placement. Notably, parents of children with SEND in primary schools reported being directed towards special schools, whereas parents of children with SEND within secondary school reported exercising greater agency. In relation to the second consideration, most parents reported wanting to make their own informed decisions rather than relying on professional guidance; interestingly, they placed greater value on the recommendations of other parents in similar situations than professional advice and distrusted professional advice and information favouring special schools (Mann, Cuskelly, and Moni, 2015). Regarding the third factor, parents of typical children reported making rational decisions 
regarding the negative and positive aspects of each setting; parents of children with SEND reported making emotional placement preference decisions, experiencing guilt, sadness and anger about their child missing out. The study by Mann, Cuskelly, and Moni (2015) highlighted the unfavourable experiences of parents of children with SEND, who reported limited choices, reduced agency and pressure to choose special schools; moreover, the whole process was emotionally overwhelming for them and their child.

Bajwa-Patel and Devecchi's (2014) mixed-method research also explored parental choice, surveying 380 families of children with SEN Statements in Southeast England. They utilised Bagley and Woods' (1998) perspective on parental decision-making, which is based on two values: instrumental-academic and intrinsic-personal/social. Parents of children with SEND may choose schools based on intrinsic values such as whether their child will feel happy, secure and included within a particular setting, whereas parents of typical children focus on academic attainment goals. Bajwa-Patel and Devecchi (2014) found the extent to which parents' exercised choice depended on their child's SEND type; most parents of children with cognitive learning difficulties reported they were given a choice by the LA, although some suggested difficulty in ensuring their choice was followed through. More than half of parents of children with behavioural, emotional and social difficulties (BESD) ${ }^{1}$ and communication and interaction needs (CIN) reported a lack of choice. Interestingly, all children with BESD attended special schools, indicating the abstractness of mainstream inclusion for children with BESD. However, parents of children with sensory and physical needs were very positive, with some suggesting that 'all schools were open for me' (Bajwa-Patel and Devecchi, 2014, p. 124).

\footnotetext{
${ }^{1}$ Bajwa-Patel and Devecchi (2014) used the term BESD in their study, which is now called social, emotional and mental health difficulties.
} 
This study highlighted the complexities parents face in expressing choice and placement decisions. There was possibly an inherent bias against the inclusion of children with BESD within mainstream schools (Bajwa-Patel and Devecchi, 2014). Whereas parents of children with BESD and CIN both reported a lack of choice, parents of children with CIN (possibly with other co-morbidities) nonetheless indicated they would retain their child's current setting; significantly, parents of children with BESD did not. This suggests that parents of children with BESD have limited options and have greater long-term dissatisfaction with their child's school placement. Parents of children with more visible forms of SEND felt more enabled by LAs, reflecting more accommodating attitudes to including children with physical needs within mainstream schools. Finally, Bajwa-Patel and Devecchi (2014) highlighted the perceived gap between policy and practice; although LAs are statutorily obliged to provide comprehensive placement information, nearly half of parents expressed this had not been done. Only LAs were ultimately able to exercise real choice within placement decision-making; their actions provided some parents with access to any school, while others were provided a very limited choice. Applying Bagley and Woods' (1998) value perspectives, Bajwa-Patel and Devecchi (2014) found that parents reported their choices were affected by intrinsic factors such as how their child would adjust in their chosen setting, their likes and dislikes and which school was most suitable for their child's needs.

These two studies reflect a disparity between policy and practice. LAs offer a choice to parents, requiring them to readjust their own expectations and aspirations of where they prefer their child to be educated. This readjustment is magnified where parents must choose between a mainstream and a special school, rather than between two mainstream schools or two special schools. Significantly, research has often synonymised inclusive experiences with mainstream experiences, implying that special schools occupy an inferior status; consequently, parents may 
believe their child will receive an 'inferior' education within special schools. Extant research has also explored how parents perceive the costs and benefits of mainstream and special schools, and their experiences of inclusion within different placement settings.

Runswick-Cole's (2007) study with 24 parents of children with SEND explored parental attitudes to inclusion and their experiences with Special Educational Needs and Disability Tribunals, found that inclusion in mainstream schools was not a straightforward decision. This study also examined how parents weigh-up the costs and benefits of both mainstream and special schools. Parents who appealed for mainstream placement stressed the importance of integration and acceptance, and displayed distrust of professional judgement and knowledge; Runswick-Cole (2007) postulates these parents were applying the social model of disability. However, parents who had appealed for special school placement were concerned by the lack of a tailored curriculum and less provisions as well as the possibility of bullying within mainstream schools. Runswick-Cole (2007) adds that parents who prefer special schools from the outset trust professional expertise, viewing their child's SEND through a medicalised lens. Ultimately, however, Runswick-Cole (2007) concedes that linking a parent's choice of mainstream or special school to a type of disability model is unjustifiably simplistic, because parental perceptions and experiences change over time.

Lindsay and Dockrell's (2004) UK-based mixed-method study questioned the relevance of pursuing inclusion as an educational policy goal. They used questionnaires and interviewed 21 parents of children in special schools and 45 parents of children attending mainstream schools. All children in this study had specific speech and language difficulties (SSLD) which can lead to behaviour problems, putting them at a higher risk of exclusion (Lindsay and Dockrell, 2004). Their study uniquely highlighted current parental experiences of provisions; parents who chose 
special schools had to fight during placement to secure their child's place, convinced that speech and language therapy would be provided as part of the daily curriculum, as opposed to mainstream schools where therapy may be once a week. Parents who chose mainstream schools fought for inclusion during placement and wanted to continue this choice into secondary education; some parents were already preparing to campaign for mainstream secondary placement. Interestingly, those parents who had chosen mainstream schools reported greater co-morbidity with SSLD, hyperactivity and conduct problems with their children than parents with children in special schools. This finding may reflect a failure by mainstream schools to adapt to these children's individual educational needs, influencing their full participation in class.

Lindsay and Dockrell's (2004) findings are similar to Runswick-Cole (2007) insofar as they agree that parents have varying goals when expressing placement preferences. Parents often prefer special schools because they believe that provisions and school support will be superior, while other parents prefer mainstream schools because they value inclusion and its positive impact on their child's social skills. This suggests that if government policy only pursues full inclusion as a goal for children with SEND, this may restrict parental placement options.

Leyser and Kirk's (2004) US-based quantitative study conducted with 437 parents, reported similar views about inclusive education and parental concerns about educational placement. Children had a range of disabilities and attended placement settings in special schools, or varying degrees of integration within mainstream schools. This study also explored the relationship between parental education levels, occupations, and the child's SEND, and their impact on parental perceptions of inclusion and mainstreaming. In similarity to Runswick-Cole (2007) and Lindsay and Dockrell (2004), parents were generally philosophically supportive of 
inclusive education; however, their child's welfare and practical constraints were central to their decision-making (Leyser and Kirk, 2004). Parents of children attending mainstream schools identified with the social benefits their child received, such as acceptance by nondisabled peers and greater self-esteem. However, they also expressed concerns about the risk of bullying and their poor impressions of the teaching skills of mainstream teachers; parents whose children attended special schools identified a better quality of instruction and one-toone support. Interestingly, Leyser and Kirk's (2004) study also revealed that while parents were happy to choose mainstream schools at primary level, parents opted for special schools at secondary level where academic and social gaps became more visible. However, parents of children with mild difficulties were more in favour of mainstream schools than parents of children with severe disabilities. Moreover, parents with a university education held more positive views of inclusive education than parents with a high school education.

Leyser and Kirk's (2004) study raises many interesting philosophical and practical points for consideration; for instance, the ideology of inclusiveness may be linked to a broader sense of an inclusive and conducive environment rather than mere placement choice. Parents choosing both mainstream and special schools during placement decision-making considered the sense of belongingness that school staff and pupils would offer their child. Leyser and Kirk's (2004) study also questions whether studies exploring the relationship between familial factors and placement choices lean towards the family deficit model (Gonzalez, Moll and Amanti, 2013), ignoring the influence of larger uncontrollable variables which impact these decisions. Finally, as children transition from primary to secondary school, their needs change; parents of children in primary mainstream schools reported considering special schools at secondary level, suggesting they valued a more tailored curriculum and independence skills training over focussing on academic achievement within a mainstream setting (Leyser and Kirk, 2004). 
These studies all found that placement decision-making is stressful for parents; however, once decision-making is over parents feel relieved and generally satisfied with their school choice and support. A recent large-scale research examining parental perceptions of UK inclusive education also supports this view; Parsons, Lewis and Ellins (2009) were part of larger project using online and postal surveys, and in-depth interviews with 125 families, with children ranging from 5 to 16 years. Approximately half of pupils attended mainstream schools, a quarter attended special schools and the remaining pupils either attended mixed settings or were home-schooled. This research compared the experiences of parents of children with autism spectrum disorder (ASD) with parents of children with other disabilities. Their findings suggest similar experiences for all parents; both sample groups reported positive support from their child's current school, most parents said their child was placed in their school of choice, and both groups were concerned about future provisions and employment opportunities. However, parents of children with ASD reported greater concerns regarding bullying and prejudice. Overall, Parsons, Lewis, and Ellins (2009) suggest that parental dissatisfaction was not significant since most parents indicated satisfaction with their child's education.

The studies reviewed so far all suggest that families face considerable challenges in securing provisions or their children with SEND (Goodley, Runswick-Cole and Mahmoud, 2013). Moreover, studies with 'Global North families' (Goodley, Runswick-Cole, and Mahmoud, 2013, p.65) assume a homogeneous experience for all parents. While some studies have focused on the influences of economic status and SEND type, very few studies have examined how the intersections of historical, political and economic contexts can lead to differing experiences for different families (Gonzalez, Moll, and Amanti, 2013). There has been little consideration of how one act of oppression (e.g., disablism) intersects with other forms of oppression (e.g., poverty). The studies discussed above do not examine experiences of families 
of children with SEND from minority and culturally-diverse backgrounds; it is important to highlight that research with minority families must avoid stereotypical notions of culture.

\section{Research aims}

My research explored how British-Pakistani mothers work with mainstream and special schools to support their child with SEND. It examined maternal preferences for special or mainstream school placements, their perception of their own responsibilities and the school's responsibility towards their child. It also explored their lived experiences and multiple positionings of British-Pakistani mothers at the intersection of religion, gender, culture and immigrant history, and how this affected mothering their child with SEND. However, this paper focuses on how the mothers in my study expressed placement preferences and experienced inclusion within different placement settings.

\section{Methodology}

This in-depth qualitative research was grounded in feminist methodology and utilised Weber's (2001) Intersectional Framework. I incorporated the feminist values of respect, reciprocity, empathy and engagement within my methodology to strengthen my critical stance. I chose research methods that would reduce the asymmetric power between myself and my participants, and would enable my participants to discuss experiences that have previously been excluded from academic discourse. I utilised a combination of unstructured time-line interviews, semi-structured interviews, and vignettes to probe how mothers navigated the UK SEN system, and their day-today experiences of supporting their child. Data collected from unstructured interviews informed subsequent semi-structured interviews and vignettes. Unstructured interviews enabled participants to describe their account of events, how they prioritised certain events (Kvale and Brinkmann, 2009), providing real insights into their 
thought processes. Interviewing is a widely used qualitative research tool, addressing 'how' and 'why' participants understand their lived experiences. Moreover, presenting my participants with vignettes which resembled their own experiences provided a neutral space for reflection without discomforting them (Spalding and Phillips, 2007). The data collection period covered 6 months, incorporating over 50 hours of interviews. Each participant was interviewed three times, allowing sufficient time to build a rapport with my participants; after my data collection, I maintained contact with those mothers who consented to remain in touch. All mothers, except one, were proficient or fluent in English; therefore, I conducted my interviews according to each mother's language preference since I am equally proficient in English and Urdu. Throughout my research journey, colleagues/supervisors constantly performed peer debriefing, checking where my interpretations required clarification; research diaries, transcripts and field notes also maintained corroboration with my participants' accounts, and checking for internal discrepancies within interviews also strengthened research credibility.

This research was conducted in Southwest England. The participants - mothers who were primary carers of children with SEND - were contacted through 'Anokha', a support group for South Asian families of children with SEND, as well as through 'snowballing'. I had initially planned to include Pakistani and Bangladeshi mothers within the sample; however, families registered with Anokha were exclusively Pakistani, particularly Mirpur-Azad Kashmir. As shown in Table 1, the mothers were either first-generation immigrants through transnational marriages or second-generation immigrants, and primarily spoke English, Punjabi and Urdu. All children, except two, had Statements. Table 2 shows that the school trajectories of the participants' 12 children at the time of data collection were that nine were in special school placements, and the remaining three were in mainstream. The tables (below) provide an overview of the mothers' profiles, their children and the types of school settings (in the 
research, pseudonyms were used in place of the actual names of the children, the mothers and their schools to protect their confidentiality).

Table 1: Participants and their family profile

\begin{tabular}{|llll|}
\hline Mothers & \multicolumn{1}{c}{ Children } & \multicolumn{1}{c|}{ Child's SEND } & \multicolumn{1}{c|}{ Mother's migrant status and profession } \\
\hline Parveen & Amber, Sehr (deceased) & Profound multiple learning difficulties & First-generation British Pakistani, Clergywoman \\
Kiran & Ahmed & Global developmental delay & Second-generation British Pakistani, School Nurse \\
Saira & Zara, Farha and Faraz & Social, emotional, mental health needs, ADHD & Second-generation British Pakistani, housewife \\
Maria & Aamir & Profound multiple learning difficulties & Second-generation British Pakistani, housewife \\
Alina & Imran & Autism & First-generation British Pakistani, medical professional \\
Maham & Daniel & Global developmental delay & First-generation British Pakistani, housewife \\
Tahira & Farrukh & Profound multiple learning difficulties & First-generation British Pakistani, housewife \\
Shehnaz & Tariq and Amna & Profound multiple learning difficulties and & Second-generation British Pakistani, housewife \\
& & global developmental delay & \\
\hline
\end{tabular}

Table 2: Children with SEND in this study

\begin{tabular}{|lll|}
\hline Name of the child & SEND level of support & \multicolumn{1}{c|}{ School trajectory } \\
\hline Farrukh (9 years) & Statement & Cavendish Special School-Chester Secondary Special School \\
Aamir $(14$ years) & Statement & Camphill Mainstream Nursery-Brindley Special Primary and Secondary School \\
Amna (9 years) & Statement & Mainstream Primary School till Y3-Chester Primary Special School \\
Tariq (6 years) & Statement & Cavendish Special School \\
Faraz (19 years) & Statement & Mainstream Primary-Southall Primary Special School-New bridge \\
& & Academy Secondary Special School \\
Farha (16 years) & School support & Canterbury Girls Trust Mainstream Secondary School \\
Zara (6 years) & School support & Darwin Primary Mainstream School \\
Sehr (deceased) $(11$ years) & Statement & Cavendish Special School \\
Amber $(6$ years) & Statement & Hilton Mainstream Primary School \\
Ahmed (15 years) & School statement & Rainbow Specialist Nursery-Chester Special School-Primary and Secondary \\
Imran $(8$ years) & Statement & Dew Mainstream Nursery-Norton Special School \\
Daniel $(7$ years $)$ & Statement & Dew Mainstream Nursery-Robin Academy Special Primary school \\
\hline
\end{tabular}

I used a pen and paper method to conduct data analysis, primarily because this method suits a small sample size. Data analysis is an iterative and reflexive process even before data collection commences (Miles, Huberman and Saldana, 2014), requiring researchers to go back and forth in the field and engaging with the literature review to generate a deeper analysis. I used Braun and Clarke's (2006) thematic analysis to conduct initial data analysis, develop codes and review themes. Since I am fluent in Urdu, interviews were transcribed directly from spoken 
Urdu into written English to save time. Copies of interview transcripts were provided to all participants, and feedback was requested regarding any discrepancies within the interview text.

\section{Ethical considerations}

I referred to BERA guidelines and the University of Bristol's ethics procedure for this research. The key issues emerging from the ethical discussion were parental consent and withdrawal, their safety and well-being, and confidentiality. I obtained ongoing consent from each participant, although the mode of consent varied. Some of my participants were uncomfortable signing a 'written document'; therefore, verbal consent on audio tape was recorded, with assurances that they would not be pressured into consenting by either Anokha or myself and could leave the research at any stage.

I ensured participants were not put at risk or discomfort throughout my research, with interviews often held at locations which protected participant privacy. Anokha knew the names and contact details of the participants they had proposed which affected their anonymity; I countered this adverse effect by allocating each participant a pseudonym in my data analysis and final report. Mothers were assured that any information they wanted withheld would be protected, and their child's name would be anonymised. Moreover, they were assured that gatekeepers and community members would not have access to their interviews. I ensured my interviews did not act as a test of my participants' parenting skills or question their parenting decisions.

For my safety, I only shared details about whom I was interviewing and where with my supervisors, with details stored in my password-protected Gmail drive. As per ethics guidelines, I plan to delete all my data once the research is published. 


\section{Findings and discussions}

This research yielded rich insights about British-Pakistani mothers' experiences in fighting for inclusion in various placement settings. Mothers wanted inclusion as an educational goal, but also wanted their child to experience belongingness in any placement setting. My findings revealed that inclusion was not tied to a specific placement setting; mothers also revealed additional factors not previously highlighted in existing studies which affected their placement preferences.

\section{Maternal views on inclusion and inclusive experiences}

Mothers interpreted inclusion beyond its locational definition, associating it with a sense of belongingness and their child's right to educational opportunities. They gave a nuanced analysis of the differences their children experienced or might experience if included within mainstream.

"In mainstream school she [Amna] was the only one who attended these [inclusion] classes, it put pressure on her. . she knows she's got special needs, but she didn't feel happy...” - Shehnaz

Shehnaz's daughter, Amna was self-conscious about being segregated from her typical classmates, and about them finding out about her specialist provision, which affected her selfesteem and peer relationships; Amna also found her timetable overwhelming. Amna's experiences question the purpose of locational inclusion if it excludes children with SEND. Notably, the mothers did not blame teachers for excluding their child, rather considered the whole system as unconducive for children with SEND; they highlighted the limited resources 
within mainstream schools and the demands on teachers in a class of 30 children. This inevitably meant that mothers faced difficult choices about leaving the system altogether in their child's best interests. Runswick-Cole's (2011) collaborative study exploring the challenges that children/young people, parents and professionals face within inclusive education found that families of children with SEND consistently experienced exclusion within mainstream schools. Despite school-wide inclusive policies, children with SEND could not access many parts of the school, and were often kept separated from typical peers (RunswickCole, 2011). Shehnaz, Maham and Parveen's experiences resonate with this 'form of apartheid of disabled pupils' (Runswick-Cole, 2011, p. 116).

Mothers were also aware how pressuring schools to perform in assessments and league tables was counterproductive to inclusive education objectives. This was reflected in Maria and Parveen's interviews.

"Some schools, they don't want their levels to drop. . and if they have children who lag behind, they can't have children bring it [performance scores] down..." - Maria

"It's idealistic, and it's great with all the opportunity but...I can't understand how they address [equality]. It doesn't make sense, equality comes with it but you can't give equality to me. It's far from reality." - Parveen

Mothers questioned whether merely placing their child within mainstream schools would provide equality. They suggested the curriculum would be incompatible for their child, and the inclusion checklist such as railings, ramps and access to playgrounds only existed on paper but not in practice; they also thought mainstream schools were not fully invested in pupils with 
SEND, because they would lower overall performance scores. Mothers said their experiences suggested that these practices were endemic within Britain's education system, but that they had ultimately accepted this. This echoes a small-scale study into schools' admissions procedures, where parents of children with SEND reported that some staff had discouraged them from applying to their schools, or implied their child would be better-off elsewhere (Office of the Children's Commissioner, 2014). In some cases, staff exploited the lack of parental awareness of the admissions process or used emotionally charged language (Office of the Children's Commissioner, 2014). However, mothers in my study seemingly knew about how SEND policy was being enacted in the context of broader educational policies, focussing on school accountability and standardisation through Ofsted inspections and SAT scores (Oliver and Barnes, 2010). Therefore, holding schools responsible for their child's inclusion was more complex, because responsibility for inclusion was shared amongst all stakeholders in the educational system.

All mothers, except Tahira and Saira, had direct or indirect negative experiences of mainstream schools. This supports findings from DeBoer, Pijl and Minnaert (2010), whose systematic review of studies probing parental attitudes to inclusion found that parents of children with SEND were hesitant about mainstream education, which affected their child's successful longterm integration. However, a nuanced analysis suggests that maternal attitudes are actually based on their child's experiences, not their own biases; this was also the case for Tahira and Saira who had both preferred mainstream inclusion.

However, although both Tahira and Saira preferred mainstream schools for their children, this did not happen. Farrukh (Tahira's son) and Faraz (Saira's son) were aware they were intentionally being sent to special schools against their wishes. 
"I understand inclusion is including everybody...that was never offered to him...ninetynine percent of why he failed was because he was made to feel different...he always wanted to be in mainstream school, he should've been given the chance...it cost money to put him in special school, to fund the staff...that could've happened in mainstream school." - Saira

While government legislation and initiatives such as SENDA (2001) and the Equality Act (2010) make it difficult for mainstream schools to refuse admission to children with SEND, Tahira and Saira's experiences suggest certain loopholes exist within the SEND Code of Practice. Tahira and Saira were both refused mainstream placements because 'the attendance of the child or young person there would be incompatible with the efficient education of others' (SEND Code of Practice, Department of Education and Department of Health, 2015, p. 172). The schools justified their decisions, citing potential classroom disruption, Faraz's resistance to taking medication, and inadequate staffing to support Farrukh's toileting. Runswick-Cole (2011) posits that such actions reflect an 'able-ist' predisposition within mainstream schools; by differentiating rather than accommodating children with SEND and assessing them against 'typical' classroom behaviour or standards, implies that children with SEND are only suited to specialist placements.

All mothers in my study experienced 'exclusion' in some way; this was social in some instances and locational in others. For instance, Shehnaz and Maham experienced first-hand the social exclusion of their children while attending mainstream schools, while Saira and Tahira's children were denied permanent mainstream placement. Uniquely within my study, Saira and Tahira fought for mainstream inclusion despite being denied access because their children's 
special school experiences had alienated them. Moreover, maternal experiences of inclusive education depended on their child's perception of where they belonged and felt happy. Shehnaz's daughter, Amna, disliked her mainstream school because she felt alienated within classroom activities; Tahira's son, Farrukh, disliked special school because he was away from his typical siblings and cousins. This important finding illustrates the need to include children's voices within the 'inclusion process' as the main stakeholders who have a right to their own individual choices (Hodkinson, 2010).

Thus far, I have discussed how mothers in my study viewed locational inclusion; they may subscribe to broader definitions of inclusion yet still prefer special school placements. This sheds new light on debates about special schools being counterproductive to inclusion. Rather than locating inclusion within mainstream schools, my findings suggest mothers focused on providing better educational and emotional experiences for their children.

\section{Factors that influence maternal placement preferences}

It is important to recall that parents can only express their placement preferences; LAs ultimately make placement decisions if their criteria are met and parents only retain the right to appeal an LA's decision through the HM Courts and Tribunals Service. At the time of data collection, my eight research participants had 12 children with SEND; eight children attended special schools, three attended mainstream schools (one was transferring to special school), and one was starting a further education college. All mothers, except Tahira and Saira, chose special schools for their child. All mothers reported a lack of choice within and between mainstream and special schools which greatly narrowed their pool of potential schools, although some mothers were likely steered towards their preferences by professional advice rather than by actively making that decision. 
Mothers sought a placement setting that best catered to their child's SEND. All mothers visited mainstream and special schools to inform their placement decisions. This supports the findings of Bagley and Woods (1998) and Jenkinson (1998) that parents consider the type and severity of their child's SEND before choosing a school with the most appropriate provision. In my study, Kiran revealed she had initially wanted her son, Ahmed, to attend mainstream school but changed her mind after considering that Ahmed was non-verbal, making it problematic for him to communicate any issues such as bullying. Kiran ultimately decided to consider only special schools with excellent speech and language therapy provisions. Similarly, Tahira reported that Farrukh had been wheelchair-bound before school-age, so she looked for schools which could help with his physical therapy and independence skills. Notably, contrary to Bagley and Woods' (1998) findings, mothers in my study also focused beyond care and provisions, and chose placements with a tailored curriculum according to their child's SEN, promoting learning at an appropriate pace.

While maternal decision-making focussed on their child's SEND, it was always combined with other factors such as professional input or transport. This reflects the realistic framework through which mothers formed their placement preferences. This is perhaps best represented in Shehnaz's comment,

"If you look at every detail, you'll never find a school. There's never going to be a perfect school that ticks every box... she's sub-par with her studies so when I found out Chester Special School took children with lower educational abilities I thought, if she fits into that I'll get a place there." - Shehnaz 
Shehnaz's experience illustrates how mothers may compromise on less important issues as long as their child's key needs are supported. This reflects how education increasingly operates in a commoditised market, with more agency granted to decision-makers (Gorad, 1999). One example of this market model is the government's initiative for local 'one-stop shops' to offer advice, support and information for families of children with SEND (Children and Families Act, 2014). Despite the freedom theoretically resulting from such marketisation, mothers in my research reported that they held limited options which meant they could exercise little free choice.

Importantly, the severity of their child's SEND did not itself prevent mothers from considering mainstream schools, rather the external environment and support offered were influencers. Amber had PMLD and a Statement, however, after receiving professional advice Parveen decided that socialising with mainstream children would benefit Amber, and so chose mainstream placement. My research also found that mothers preferred special schools because they wanted better provisions and a tailored curriculum for their child, echoing studies by Lindsay and Dockrell (2004) and Runswick-Cole (2007). However, the two mothers in my study who preferred mainstream did so not just due to inclusion, but also because they believed their child had a right to mainstream education, an aspect not previously found.

Another uniquely revealing finding was that, given an option between two special schools, mothers were more likely to prefer a special school that looks less sanitised and disabling. This was reflected in interviews with Maria, Parveen and Shehnaz as they discussed actively visiting all special schools. 
"We visited Cavendish and Brindley [special schools]. At Cavendish I came out crying, I couldn't send Aamir to that school, most children were in wheelchairs and Aamir had just started using his wheelchair but wasn't full-time, I was thinking to go to a setting where the norm was for everybody to use wheelchairs...I wasn't happy." - Maria

In my earlier study (Rizvi, 2015), mothers also discussed the negative visual imagery of disability as their child first entered special school, which mothers perceived as their child's segregation from 'normal'. However, maternal perceptions had been unaffected by the 'physical' aspects of special schools (Rizvi, 2015). Existing studies have explored the visual imagery of disability in relation to the media, public spaces, children's literature and charity representations (Garland-Thomson, 2002). Moreover, Bagley, Woods and Woods (2001) found that parents of typical children did consider the school environment during placement decision-making, however, significantly literature specifically exploring whether the physical environment within special schools affected placement preferences is scarce. Although mothers in my study chose special schools for their child, they preferred schools which did not resemble a hospital, projecting feelings of 'hopelessness and sickness'. Maria suggested she was more likely to prefer a special school that was closer to her impression of her 'own sense of normal'. This suggests that special schools should rethink aspects of their physical environment to appear more inclusive and welcoming to children and mothers.

Another factor affecting maternal special school placement preferences was shared geographical proximity or resources with mainstream schools. Sharing playgrounds or resources such as swimming pools with mainstream schools provided opportunities for children with SEND to socialise with typical children and enjoy the 'best of both worlds' (Parveen, second interview). This contradicts Runswick-Cole (2007) who found that mothers 
who preferred special school placement operated from a medicalised model of disability. In seeking aspects of locational and social integration (Shah, 2007) with typical children, mothers in my study acknowledged the benefits of mainstream schools. This was further validated when many mothers confirmed they desired eventual mainstream integration, but preferred special school placement during their child's primary years to avail specialist intervention and support to develop essential independence and social skills, which would help their child's eventual inclusion into mainstream society.

A third factor influencing maternal preferences was professional advice. Except Alina, all mothers revealed how educational, medical and care professionals either helped or hindered their placement decision-making, advising them about better choices or excessively encouraging a particular placement setting (Mann, Cuskelly, and Moni, 2015). In my previous study, I found that mothers had accepted advice from medical professionals to choose special schools in their child's best interest, in the absence of alternative information (Rizvi, 2015). Mothers in my current research did not similarly adhere to advice from medical professionals, although Shehnaz, Maria and Parveen did believe that medical professionals were sincere, forming part of their 'information circle'; they helped Shehnaz choose a special school for Tariq, and helped Parveen choose a mainstream school for Amber. Reliance on medical professionals during placement may be because mothers had worked closely with them for a prolonged period due to the nature and severity of the child's SEND.

Where advice from LAs or schools differed from maternal preferences, then mothers felt betrayed and coerced into making a particular choice, as in Tahira and Saira's case. 
“The school was sold to me as a fantastic opportunity for Faraz where he'd progress. I didn't know any different, I thought, I want the best for my child so I signed him up." - Saira

Both Saira and Tahira reported being actively dissuaded by educational professionals from considering mainstream school and pushed into considering a special school. Similarly, the Office of the Children's Commissioner (2014) also found that parents reported that mainstream schools expressed they lacked sufficient resources after learning their child had a Statement. Although it is now unlawful for schools to refuse children due to inadequate support, research by Office of the Children's Commissioner (2014) and Byrne (2013) both suggest mainstream schools still discourage parents who they consider incompatible with their profile from applying, or transfer them later to special schools.

A fourth factor influencing maternal preferences was transport and the travelling distance to schools. Previous studies have highlighted these factors as influencing school choices, although not specifically families of children with SEND. For instance, Gorad (1999) suggests school location and transport can have a greater influence on families who lack placement options or have transport-related difficulties; this was less significant for more affluent families. I found mothers in my study favoured schools within close proximity because this would aid communication, would help to be within reach of their child in medical emergencies, and would ease their school runs for their other children at different schools. Tahira also suggested her other caring responsibilities and her inability to drive meant she needed school transport for Farrukh. 
The final factor affecting maternal placement decision-making, although to a lesser degree, was family influence. As first-generation immigrants, Maham and Tahira both suggested their unfamiliarity with Britain's educational system was the reason they relied on their BritishPakistani in-laws to guide them in placement decision-making. However, while Maham undertook a collaborative effort with her sister-in-law, Tahira had decisions imposed on her by her father-in-law. Nonetheless, neither mother reported that family involvement had lessened their satisfaction with their child's final placement settings, possibly because they both lived with their in-laws and criticising such 'family' decisions would have adversely affected their family positioning. Therefore, schools and LAs should ensure that mothers are au fait with all facets of the placement process, directly interacting with them so that they are less reliant on family and friends to represent them. Although language barriers were not a prominent theme in my study, where they do exist with mothers, this may require the use of interpreters or language-appropriate literature which can also be made available to download online. This would enable mothers to make fully informed decisions regarding what they see as ideal for their child.

All mothers in my study understood the complexity of exercising their placement choice, and desired educational settings that were in their child's best interests. Mann, Cuskelly, and Moni (2015) suggest three main factors characterise school choices: agency and constraints on individual choice; the perceived value of liberty and professional input; and rational and emotional aspects to decision-making. Applying these factors to my findings, firstly, all mothers reported constraints on free choice with very few mainstream and special schools to choose from. However, mothers did exercise agency, actively fighting for inclusive spaces for their children within mainstream and special schools. Moreover, all mothers suggested they wanted to make their own decisions based on their information circle, rather than relying solely 
on professional opinions. Although Saira had been pushed by educational practitioners into accepting special school placement for Faraz, after the detrimental professional treatment that Faraz received she was determined to form her own opinions regarding her daughters, Farha and Zara. Finally, mothers recognised their responsibility towards placement decision-making; they viewed Statements as a means to getting special school placements and appropriate support for their child, and therefore, were committed to ensuring their voices were being heard. Additionally, mothers suggested that 'gathering proof' and working alongside or often against professional opinion was emotionally exhausting, however, they had to quickly get 'back to reality' (Alina, first interview) because they had multiple roles and responsibilities towards their child.

\section{Conclusion}

This research uniquely identified the broader roles that mothers expected mainstream and special schools to play with regard to inclusion. Mothers with children in special schools wanted the school to provide a genuine opportunity to transition into mainstream school. This deviates from Runswick-Cole (2007), who suggested that the maternal lens is shaped by the medical model of disability if parents chose special schools, and concurs with research which report that models of disability do not reflect parental placement choices. Therefore, mothers in my study sought the placement setting which promised the most support and best provisions for their child's learning. Parents also wanted special schools to provide meaningful progression for their child into adulthood by offering mainstream transition. This included considering schools which provided a curriculum that encouraged their child's learning at an appropriate pace rather than just focusing on care. While most children in my study attended a special school, many mothers indicated that the choice of special schools was very limited and that they had picked the school which looked least disabling. This has important implications 
for practitioners working in special schools, and for how parents consider visual imagery when making placement decisions.

Maternal placement preferences were also influenced by professionals, families and transport issues, reinforcing the views of existing studies on the importance of providing correct guidance to parents, rather than relying on the opinions and expertise of others to make a placement preference. This research reveals that final placement settings did not always necessarily reflect original parental preferences, nor did current placement settings exactly match maternal expectations of the ideal school for their child. Mothers often had to adjust their expectations to an imperfect education system and negotiate with the school about available resources to ensure that their child received the best possible support from the school. While there is limited research on how ethnic-minority parents, specifically mothers, experience placement decision-making, my research reveals that schools and the educational system in general, must take practical steps to make the placement decision-making process more inclusive if they are committed to providing greater choice, control and support to all parents. This may require LAs to provide mothers with an education welfare officer who offers impartial advice and information during the placement process. This guidance should be free from professional jargon and ensure that mothers from diverse communities who may be unfamiliar with the current SEND Code of Practice and the nuances of the special education system are not disadvantaged at this crucial stage of their child's education. It also means that at the time of school placement, children's voices are the centre of this process; the experiences of Farrukh and Faraz highlight the repeated silencing of children's wishes regarding their own placement settings. In addition, schools need to work with and value maternal expertise on how best to support their child in their current settings. Finally, as opposed to focusing on inclusion as the end-goal, mainstream and special schools need to work in partnership rather than as 
separate ideological camps to share resources, expertise and best practices if they want to bring about the best possible outcomes for children with SEND.

\section{Address for correspondence:}

Dr. Sana Rizvi

De Montfort University

Room 1.23, Portland Building

The Gateway, Leicester LE1 9BH, UK.

Email: sana.rizvi@dmu.ac.uk.

\section{References}

Bagley, C. \& Woods, P. (1998) 'School choice, markets and special educational needs.' Disability \& Society,

$13(5)$, pp. 763-83.

Bagley, C., Woods, P. A. \& Woods, G. (2001) 'Implementation of school choice policy: interpretation and response by parents of students with special educational needs.' British Educational Research Journal, 27 (3), pp. 287-311.

Bajwa-Patel, M. \& Devecchi, C. (2014) ' Nowhere that fits': the dilemmas of school choice for parents of children with Statements of special educational needs (SEN) in England.' Support for Learning, 29, pp.117-35.

Braun, V. \& Clarke, V. (2006) 'Using thematic analysis in psychology.' Qualitative Research in Psychology, 3

(2), pp. 77-101. 
Byrne, A. (2013) 'What factors influence the decisions of parents of children with special educational needs

when choosing a secondary educational provision for their child at change of phase from primary to secondary education? A review of the literature.' Journal of Research in Special Educational Needs, 13, pp. 129-41.

Children and Families Act (2014) Norwich: The Stationary Office. <http://www.legislation.gov.uk/ukpga/2014/6/pdfs/ukpga_20140006_en.pdf> (accessed 10 January 2017).

De Boer, A.A., Pijl, S.J., Minnaert, A.E. (2010). Attitudes of parents towards inclusive education: A review of the literature. European Journal of Special Needs Education, 25(2), $165-181$.

Department of Education and Department of Health (2015) Special educational needs and disability code of practice: $0-25$. <https://www.gov.uk/government/uploads/system/uploads/attachment_data/file/398815/SEN D_Code_of_Practice_January_2015.pdf> (accessed 10 January 2017).

Equality Act (2010) London: The Stationery Office Limited. <http://www.legislation.gov.uk/ukpga/2010/15/pdfs/ukpga_20100015_en.pdf> (accessed 10 January 2017).

Garland-Thomson, R. (2002) 'The politics of staring: visual rhetorics of disability in popular photography.' In S. L. Snyder, B. J. Brueggmann \& R. Garland-Thomson (eds), Disability Studies: Enabling the Humanities, pp. 56-75. New York, NY: The Modern Language Association of America.

Gonzalez, N., Moll, L. C. \& Amanti, C. (2013) Funds of Knowledge: Theorizing Practices in Households, Communities, and Classrooms. New York, NY: Routledge. 
Goodley, D., Runswick-Cole, K. \& Mahmoud, U. (2013) 'Disablism and diaspora: British Pakistani families and disabled children.' Review of Disability Studies: An International Journal, 9 (2/3), pp. 63-78.

Gorad, S. (1999) 'Well, that about wraps it up for school choice research': a state of the art review.' School Leadership and Management, 19 (1), pp. 25-47.

Hodkinson, A. (2010) Inclusive and special education in the English educational system: Historical perspectives, recent developments and future challenges. British Journal of Special Education, 37(2), pp. 61-67.

Jenkinson, J. (1998) 'Parental choice in the education of students with disabilities.' International Journal of Disability, Development and Education, 45 (2), pp.189-202.

Kvale, S. \& Brinkmann, S. (2009) Learning the Craft of Qualitative Research Interviewing. Thousand Oaks, CA: Sage Publications.

Leyser, Y.\& Kirk, R. (2004) 'Evaluating inclusion: an examination of parent views and factors influencing their perspectives.' International Journal of Disability, Development and Education, 51 (3), pp. 271-85.

Lindsay, G. \& Dockrell, J. E. (2004) 'Whose job is it? Parents' concerns about the needs of their children with language problems.' The Journal of Special Education, 37 (4), pp. 225-35. Mann, G., Cuskelly, M. \& Moni, K. (2015) 'Choosing a school: parental decision-making when special schools are an option.' Disability \& Society, 30 (9), pp. 1413-27.

Miles, M. B., Huberman, A. M. \& Saldana, J. (2014) Qualitative Data Analysis: A Methods Sourcebook. London: SAGE Publications, Incorporated.

Office of the Children's Commissioner (2014) A Rights-Based Approach to Education. Office of the Children's Commissioner. <www.childrenscommissioner.gov.uk/> (accessed 10 January 2017). 
Oliver, M. \& Barnes, C. (2010) 'Disability studies, disabled people and the struggle for inclusion.' British Journal of Sociology of Education, 31 (5), pp. 547-60.

Parsons, S., Lewis, A. \& Ellins, J. (2009) 'The views and experiences of parents of children with autistic spectrum disorder about educational provision: comparisons with parents of children with other disabilities from an online survey.' European Journal of Special Needs Education, 24 (1), pp. 37-58.

Rizvi, S. (2015) 'Exploring British Pakistani mothers' perception of their child with disability: insights from a UK context.' Journal of Research in Special Educational Needs, 17 (2), pp. 8797.

Runswick-Cole, K. (2007) 'Between a rock and a hard place: parents' attitudes to the inclusion of children with special educational needs in mainstream and special schools.' British Journal of Special Education, 35 (3), pp. 173-80.

Runswick-Cole, K. (2011) ‘Time to end the bias towards inclusive education?' British Journal of Special Education, 38 (3), pp. 112-9.

SENDA (2001) Special Educational Needs and Disability Act c10. London: Stationery Office.

Shah, S. (2007) 'Special or mainstream? The views of disabled students.' Research Papers in Education, 22

(4), pp. 425-42.

Spalding, N. J. \& Phillips, T. (2007) 'Exploring the use of vignettes: from validity to trustworthiness.' Qualitative Health Research, 17 (7), pp. 954-62.

Weber, L. (2001) Understanding Race, Class, Gender and Sexuality: A Conceptual Framework. Boston, MA: McGraw Hill. 